\title{
Suppression of spring rain by surface greening over North China Plain
}

\author{
Xuezhen Zhang, ${ }^{\text {a* }}$ Qiuhong Tang, ${ }^{a}$ Jingyun Zheng, ${ }^{a}$ Quansheng Ge ${ }^{\mathrm{a}}$ and Rui Mao ${ }^{\mathrm{b}}$ \\ ${ }^{a}$ Key Laboratory of Land Surface Pattern and Simulation, Institute of Geographical Sciences and Natural Resources Research, Chinese Academy \\ of Sciences, Beijing, China \\ b State Key Laboratory of Earth Surface Processes and Resource Ecology, Beijing Normal University, China
}

\begin{abstract}
Surface greenness and rainfall in spring have changed from the 1980s to 1990s over the North China Plain (NCP). The greenness changes are characterized by large increase in north and little in south with an obvious greening zone from the centre of the NCP to the northeast. The rainfall change has a similar spatial pattern with reversed sign. The correlation between changes in greenness and rainfall is significant and the correlation $(r=-0.71, p<0.001)$ is highest for light rainfall. The number of light rainfall days decreased by only $\sim 10 \%$ at the stations where the Normalized Differences Vegetation Index (NDVI) did not change, whereas it decreased by up to $\sim 30 \%$ at the stations where NDVI increased by $20 \%$. Further analyses found that surface greening increased evaporation wetting the atmosphere and, meanwhile, reduced sensible heat flux to cooling surface air. The cooling surface promotes the air stability and thus suppresses the occurrence of rainfall. This finding supports that surface cooling effects from greening play a more dominant role on occurrence of spring rainfall than the wetting effect in the NCP.
\end{abstract}

KEY WORDS surface greening; North China Plain; spring rainfall; air stability

Received 21 December 2013; Revised 19 August 2014; Accepted 20 August 2014

\section{Introduction}

The North China Plain (NCP) is an important agricultural area that provides over $75 \%$ of China's wheat and $35 \%$ of China's maize production (National Bureau of Statistics of China, 2009). Spring drought is a main threat to crop yield in the NCP (Chen and Yang, 2013). A large number of studies have been performed to understand the influencing factors of spring rainfall in this region (e.g. Yang and Lau, 2004; Choi et al., 2010; Wang et al., 2010; Zhao et al., 2012). Many of these studies focused on the role of the large-scale atmospheric circulations and relevant moisture transportations. For instance, Yang and Lau (2004) reported that the warm anomaly of sea surface in the tropical Indian Ocean and the warm pool could lead to stronger south and southeast wind and thus bring more warm and moist air to the NCP. Zhao et al. (2012) found that the strength and position of trough and ridge over the East Asia could modulate the moisture transportation to North China. Choi et al. (2010) showed that decrease in snow depth at the mid-latitude could restrict the northern movement of the subtropical anticyclone and prevent the inflow of warm and humid air to the NCP area. Zhou and Zhao (2010) pointed out that land-ocean contrast might regulate spring rainfall through modifying the large-scale

\footnotetext{
* Correspondence to: X. Zhang, Key Laboratory of Land Surface Pattern and Simulation, Institute of Geographical Sciences and Natural Resources Research, Chinese Academy of Sciences, Beijing 100101, China. E-mail: xzzhang@igsnrr.ac.cn
}

circulation pattern and moist transportation over the East Asia. A few studies reported that land surface change also exerts spring rainfall over NCP through thermodynamics and thus regulating the atmospheric circulation. For instance, Wang et al. (2010) found that vegetation changes in the Tibetan Plateau may modify air motions over the Plateau through thermodynamics processes. As a result, there is an anomalous cyclonic circulation in the lower troposphere over the NCP and, finally, the spring rainfall is regulated. As mentioned above, the existing studies explained partly the rainfall changes over the entire NCP, using the large-scale circulation and relevant moisture transportation. However, few studies focus on spatial differences of rainfall changes across the NCP. We also know little about the roles of spring greenness change on the local rainfall changes.

The spring surface greenness, as indicated by the Normalized Differences Vegetation Index (NDVI), increased in the NCP over the last two decades of the 20th century, likely due to climate warming and field management (e.g. Piao et al., 2003; Peng et al., 2011). It has been reported that the greening surface has a cooling effect, particularly on the day time (e.g. Jeong et al., 2009a, 2009b; Zhang et al., 2013). The existing studies find that the cooling effect is derived from more evportranspiration, i.e. latent heat flux, and less sensible heat flux over the greening surface. The surface moisture/heat flux to atmosphere may regulate the moisture-thermal-dynamic of low-level atmosphere which is closely related to occurrence of rainfall. 
However, we know little for the effects of changes in surface greenness on local rainfall for the NCP.

Kim and Wang (2007) reported that vegetation reinforces the positive feedback of wet soil moisture anomaly on precipitation in summer while suppresses the summer precipitation following the wet soil moisture in spring. Wang et al. (2011) and Sun and Wang (2014) found a positive feedback between local precipitation and vegetation growth, and draw conclusion that the dynamical vegetation plays positive role on enhancing precipitation variability in Amazon. Notaro et al (2011) reported that there are unique responses to reduced vegetation cover among the monsoon regions, and that precipitation increase in spring and decrease in summer over the China mainland. Jiang et al. (2009) also found a significant regulation of dynamical vegetation on summer precipitation in central United States. These findings were mostly derived from simulations of coupled models, whereas there were rarely the observation-based studies. It is necessary to perform more studies using the essential observations to diagnose the essential effects of surface greenness changes on local rainfall. Wang et al. (2014) illustrated a light precipitation increase in spring as the response to surface greening over the North American Monsoon Region. These potential effects have not been confirmed by observations in the NCP.

This study is motivated to investigate the effects of surface greening on local spring rainfall in the NCP by analysing the rainfall and vegetation index at the meteorological stations. The atmospheric reanalysis data were used to study the possible mechanisms linking the changes in surface greenness and rainfall.

\section{Data and methods}

In this study, the NCP refers to the plain area in the domain of $32.5^{\circ} \mathrm{N}-40^{\circ} \mathrm{N}, 112^{\circ} \mathrm{E}-122^{\circ} \mathrm{E}$ (Figure $1(\mathrm{a})$ ). We focused on the decadal changes in spring (March to May) rainfall and surface greenness from 1980s to 1990s because this period had the largest decadal changes in surface greenness within the last three decades (Peng et al., 2011). The meteorological sites used in this study were selected from the available China Meteorological Administration (CMA) sites using the following criteria: (1) no missing observations from March to May in the period of 1982-2001; (2) altitude lower than $400 \mathrm{~m}$ to ensure the site falls in the plain; and (3) being outside of urban areas to exclude impacts of urban. The urban area was identified using the land use data set of China, which was created using the Landsat TM digital images and China-Brazil Earth Resources Satellite 1 data (Liu et al., 2003). In total, 41 sites were selected (Figure 1). We investigated three categories of rainfall which was identified by the daily rainfall $\left(R_{\mathrm{d}}\right)$ : light rainfall $\left(0.1 \mathrm{~mm}<R_{\mathrm{d}}<10 \mathrm{~mm}\right)$, moderate rainfall $\left(10 \mathrm{~mm} \leq R_{\mathrm{d}}<25 \mathrm{~mm}\right)$ and heavy rainfall (25 mm $\leq R_{\mathrm{d}}<50 \mathrm{~mm}$ ) (Editor Board, 2009). We calculated the annual spring rain days (rainfall frequency) and rainfall amount for each grade.
The NDVI data used by this study were obtained from the Global Inventory Monitoring and Modeling Studies (GIMMS) group. The GIMMS NDVI data were derived from the NOAA/AVHRR Land data set, and have a spatial resolution of 8 - by $8-\mathrm{km}$ and a temporal interval of 15 days for the period from 1982 to 2006 (Tucker et al., 2001, 2005; Zhou et al., 2001). The data had been widely verified and used to investigate the surface greenness change in China (e.g. Piao et al., 2003; Peng et al., 2011). In this study, a $3 \times 3$ pixels window around the meteorological site was used to calculate the spring mean NDVI at each site (refer to site-based NDVI, hereafter). As well as, the pixels covered by a 0.5 - by 0.5-degree grid cell of European Centre for Medium-Range Weather Forecasts reanalysis data (ERA-Interim) were used to calculate the spring mean NDVI of each cell (refer to cell-based NDVI, hereafter).

This study also used the monthly mean air temperature $(T)$ and specified humidity $(H)$ at pressure levels of 850 and $500 \mathrm{hPa}$ and surface evaporation $(E)$, sensible heat flux $(\mathrm{SH})$, and latent heat flux $(\lambda E)$ to atmosphere, which were taken from the latest reanalysis of the ERA-Interim with a $0.5^{\circ}$ grid (Dee et al., 2011). The difference in air temperature between the two pressure levels $(T 850-T 500)$ was used to represent the air column instability, the higher the unstable. The air column instability, specified humidity at pressure level of $850 \mathrm{hPa}(H 850)$, surface $E, \lambda E$, and $\mathrm{SH}$ at the site-located grid cell were used at each site.

Using the above-mentioned annual spring mean values, we calculated the decadal differences from 1982-1991 (the 1980s, hereafter) to 1992-2001 (the 1990s, hereafter) of the rain days, rainfall amount, NDVI, air instability, $H 850, E, \mathrm{SH}$, and $\lambda E$. The two-sample $t$-test was applied to examine the significance of these differences. Then, to analyse the effects of surface greenness on rainfall, we calculated the correlations between the changes in site-based NDVI and those in rain days and rainfall amount, respectively. To diagnose the potential mechanism through which surface greenness regulates rainfall, we calculated the correlations between the changes in cell-based NDVI and those in air column instability, $H 850, E, \mathrm{SH}$, and $\lambda E$, respectively, to reveal out the regulations of surface greenness on surface energy/moisture flux and air column instability; finally, we calculated the correlations between the changes in rainfall days/amount and in moisture and air column instability, respectively.

\section{Results}

\subsection{Observed changes in spring NDVI and rainfall}

Figure 1(a)-(e) shows the changes in spring NDVI and rainfall frequency for all the cropland sites in the NCP from the 1980 s to 1990 s. There are 32 sites with increased NDVI and the increases are significant $(p<0.1)$ at 21 sites. The increased NDVI spreads over the most of NCP. It is indicated that surface greening extensively occurred across the NCP. However, the greening strength had large spatial difference. We could found an obvious greening zone, 

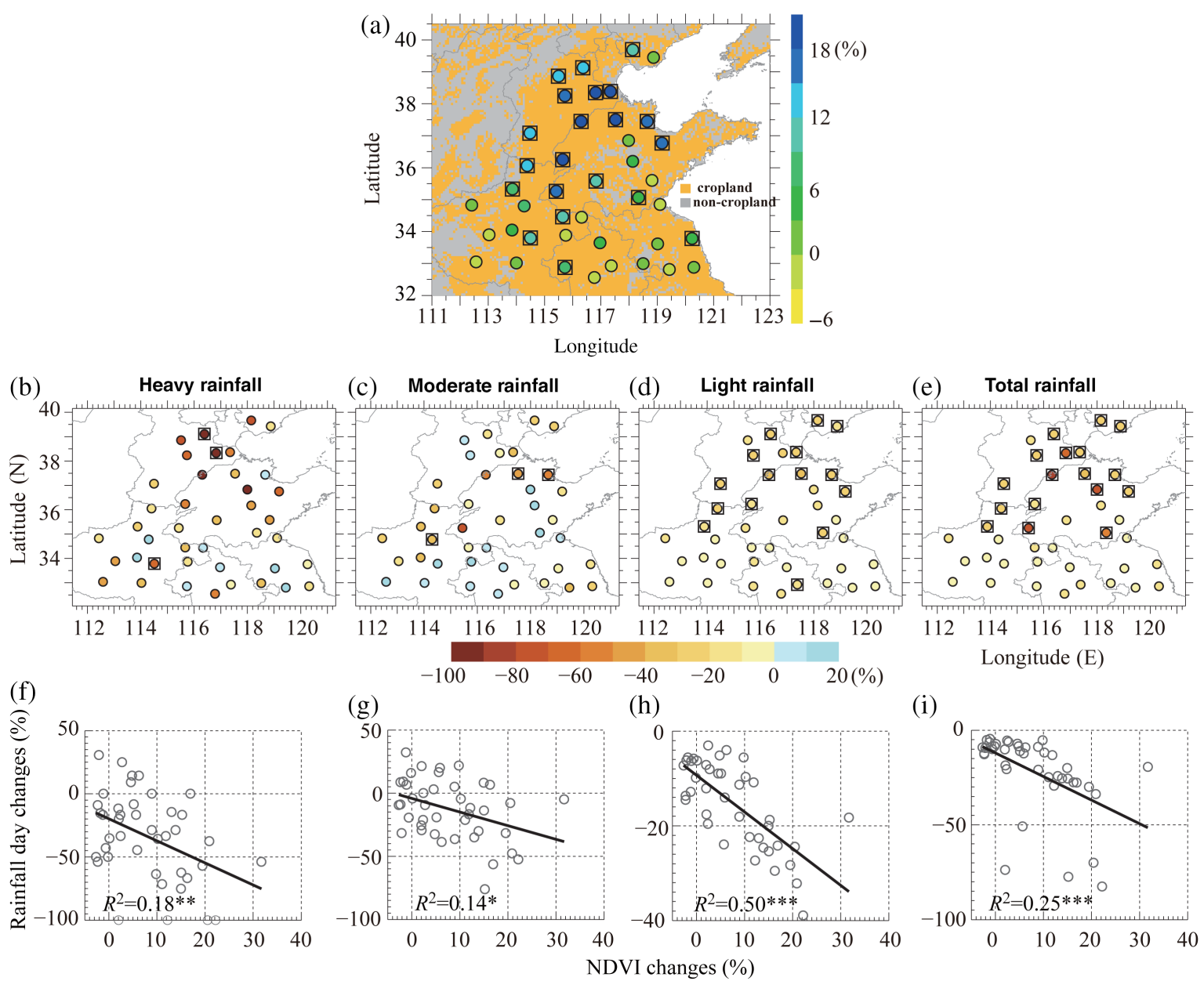

Figure 1. Changes in NDVI surrounding the meteorology sites (a) and in heavy rainfall frequency (b), moderate rainfall frequency (c), light rainfall frequency (d), and total rainfall frequency (e) from 1980s to 1990s (1990s - 1980s; hollow square represents change is significant at the level of $90 \%$ ), and correlations between changes in NDVI and in heavy rainfall frequency (f), moderate rainfall frequency ( $\mathrm{g}$ ), light rainfall frequency (h), and total rainfall frequency (i) $(*, * *$, and $* * *$ represent correlation is significant at the levels of $95 \%, 99 \%$, and $99.9 \%$, respectively).

where NDVI significantly $(p<0.1)$ increased by over $20 \%$, from the centre of the NCP to the northeast (Figure 1(a)). There are a few sites with decreased NDVI, which mostly locate in the south part of the NCP. Rainfall changes were extensively characterized by the decrease from the 1980s to 1990 s across the NCP. The decreases in the heavy, moderate, and light rainfall days occurred at 33, 27, and 41 sites, and the significant $(p<0.1)$ decreases were detected at 3, 3, and 15 sites, respectively. As well as, the changes in rainfall frequency/amount exhibited large spatial difference. There was large decrease in north and little decrease in south. A great decreasing zone existed from the centre of the NCP to the northeast (Figure 1(b)-(e)). The pattern of rainfall amount changes (Figure 2) resembles that of rainfall frequency changes (Figure 1(b)-(e)).

The correlations between the changes in NDVI and rainfall days are significantly negative (Figure 1(f)-(i); Table 1). It is demonstrated that large (small) surface greening coexisted with large (small) decrease in rainfall. The correlations is highest $(r=-0.71, p<0.001)$ for light rainfall. The light rainfall days decreased by $\sim 10 \%$ at the stations where greenness did not change, whereas it decreased up to $30 \%$ at the stations where NDVI increased by $20 \%$. The sensitive analysis shows that the light rainfall days would decrease by more $\sim 10 \%$ corresponding to a NDVI increase by $10 \%$. The light rainfall amount would as well as decrease by more $\sim 10 \%$ corresponding to a NDVI increase by $10 \%$ (Figure 2 ). There are also significantly negative correlations for heavy and moderate rainfall days $(r=-0.42, p<0.01 ; r=-0.37, p<0.05$, respectively), even though the correlations are relative weak. The correlations for total rainfall days is significant $(r=-0.50, p<0.001)$ too. The sites with an increase of $10 \%$ NDVI would experience total rainfall days decrease by more $\sim 10 \%$ (Figure 1(i)) and total rainfall amount decrease by more $\sim 15 \%$ (Figure 2 ) in the NCP.

3.2. Effects of spring NDVI on the air humidity and instability of air column

Figure 3 illustrates the changes in spring NDVI and surface moisture/heat fluxes from the 1980s to 1990s for all of cropland grid cells over the NCP. Corresponding to the NDVI increase, the surface moisture flux to atmosphere increased and sensible heat flux to atmosphere decreased across the NCP. It is highlighted that there are significant correlations between the changes in NDVI and in 

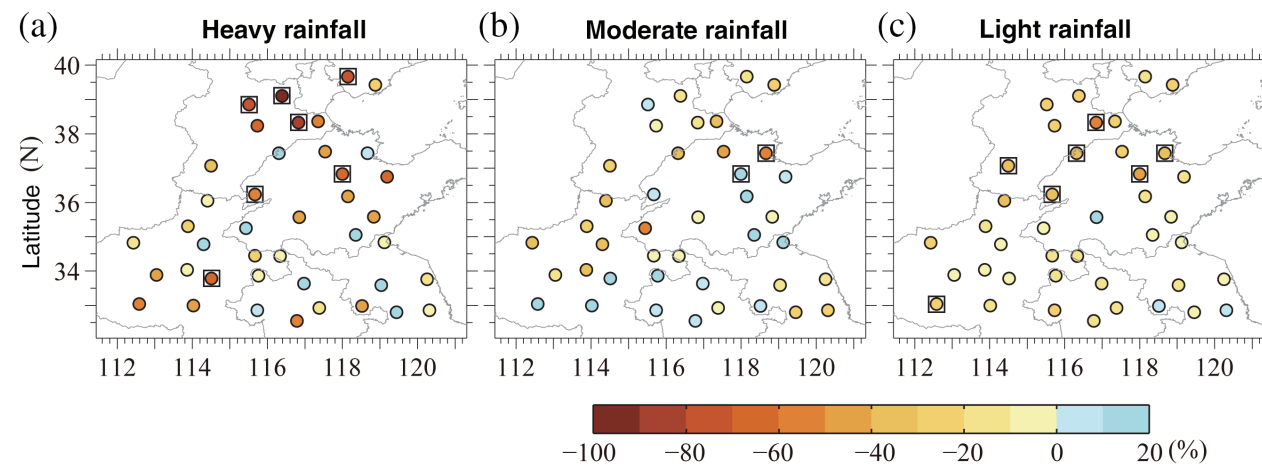

(e)

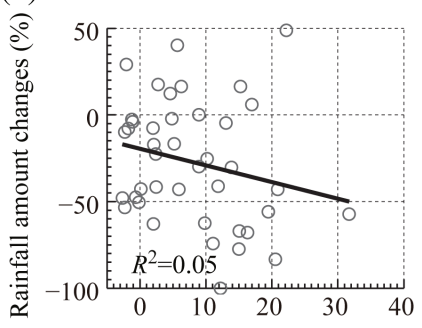

(f)

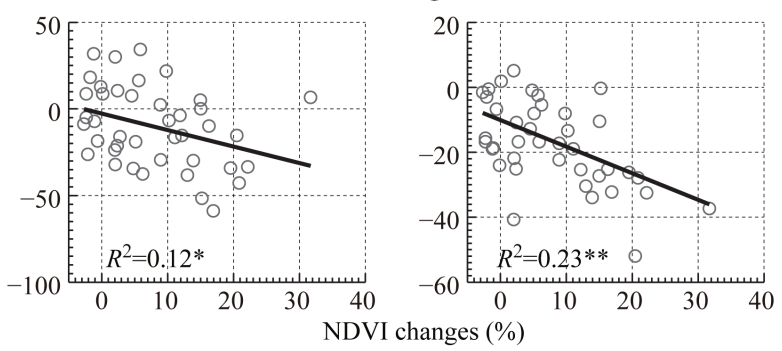

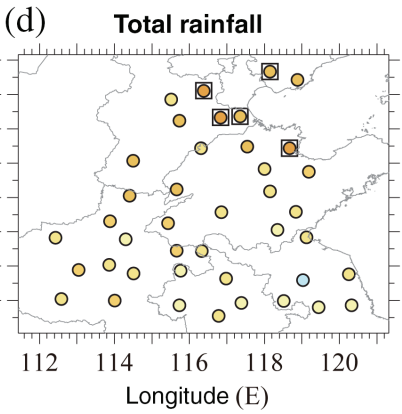

(d) Total rainfall

(h)

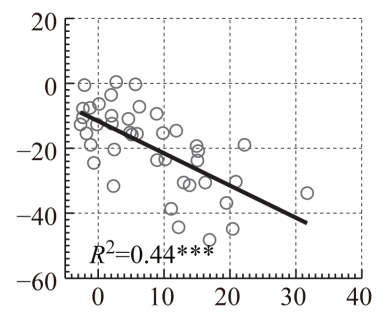

Figure 2. Changes in heavy rainfall amount (a), moderate rainfall amount (b), light rainfall amount (c), and total rainfall amount (d) from 1980s to 1990s (1990s - 1980s; hollow square represents change is significant at the level of 90\%), and correlations between changes in NDVI and in heavy rainfall amount (e), moderate rainfall amount (f), light rainfall amount $(\mathrm{g})$, and total rainfall amount $(\mathrm{h})(*, * *$, and *** represent correlation is significant at the levels of $95 \%, 99 \%$, and $99.9 \%$, respectively).

Table 1. Correlation coefficients between the changes in rainfall and in NDVI.

\begin{tabular}{lcccc}
\hline & Heavy rainfall & Moderate rainfall & Light rainfall & Total rainfall \\
\hline Rainfall days & $-0.42 * *$ & $-0.37 *$ & $-0.71 * * *$ & $-0.50^{* * * *}$ \\
Rainfall amount & -0.22 & $-0.35^{*}$ & $-0.48^{* *}$ & $-0.66^{* * *}$ \\
\hline
\end{tabular}

$*, * *$, and $* * *$ represent correlation is significant at the levels of $95 \%, 99 \%$, and $99.9 \%$, respectively.

surface moisture/heat fluxes. Significant positive correlations $(r=0.55, p<0.001)$ exist between the changes in NDVI and in evaporation/latent heat flux. The evaporation would increase by more $\sim 0.16 \mathrm{~mm}$ and surface latent heat flux increased by more $\sim 4.66 \mathrm{~W} \mathrm{~m}^{-2}$ corresponding to NDVI increase by 0.1 . Reversely, a negative correlation ( $r=-0.63, p<0.001$ ) exist between the changes in NDVI and in surface sensible heat flux. Sensible heat flux would decrease by more $\sim 5.43 \mathrm{~W} \mathrm{~m}^{-2}$ corresponding to NDVI increase by 0.1 . These correlations suggest that enhanced NDVI co-occurs with strong evaporation/latent heat flux and weak sensible heat flux to atmosphere. This finding is as well as supported by JRA-25 reanalysis (Jeong et al., 2009a) and WRF model simulation (Zhang et al., 2013).

The low-level atmospheric conditions are closely related to the surface moisture/heat fluxes. As the response to the above changes in moisture/heat fluxes resulted from surface greening, there are significant correlations between the changes in NDVI and in low-level atmospheric humidity/temperature from the 1980s to 1990s. Corresponding to the more evaporation from high NDVI (Figure 3(a)), a significantly positive correlation $(r=0.46, p<0.001)$ exists between the changes in NDVI and in $H 850$ (Figure 4(a)). Large (small) increase in NDVI coexists with less (large) decrease in $H 850$. Corresponding to the more latent heat flux and less sensible heat flux from high NDVI (Figure 3(b) and (c)), a significantly negative correlation ( $r=-0.28, p<0.01)$ exists between the changes in NDVI and in $T 850$ (Figure 4(b)). Large (small) increase in NDVI coexists with small (large) warming. These correlations suggest that vegetation may lead to cooling and wetting surface air through producing more evaporation and less sensible heat flux, as the simulation results from CAM-CLM model (Lee et al., 2011). Such a cooling and wetting effect in spring resulted from surface greening was also reported by Jeong et al. (2009a, 2009b) and Zhang et al. (2013).

Up to the pressure level of $500 \mathrm{hPa}$, the changes in T500 had little correlation with changes in surface NDVI (Figure 4(c)). As the changes in T850 is significantly correlated with surface heat flux, change in the air column instability which is represented as T850-T500 is significantly negative correlated with changes in NDVI $(r=-0.37, p<0.001)$. The small (large) increases in instability occurred along with large (small) increase in NDVI (Figure 4(d)). It could be explained by that large greening lead to cooling surface through producing more latent heat flux and less sensible heat flux. Such a negative correlation suggests that greening surface favours to stable atmosphere. 

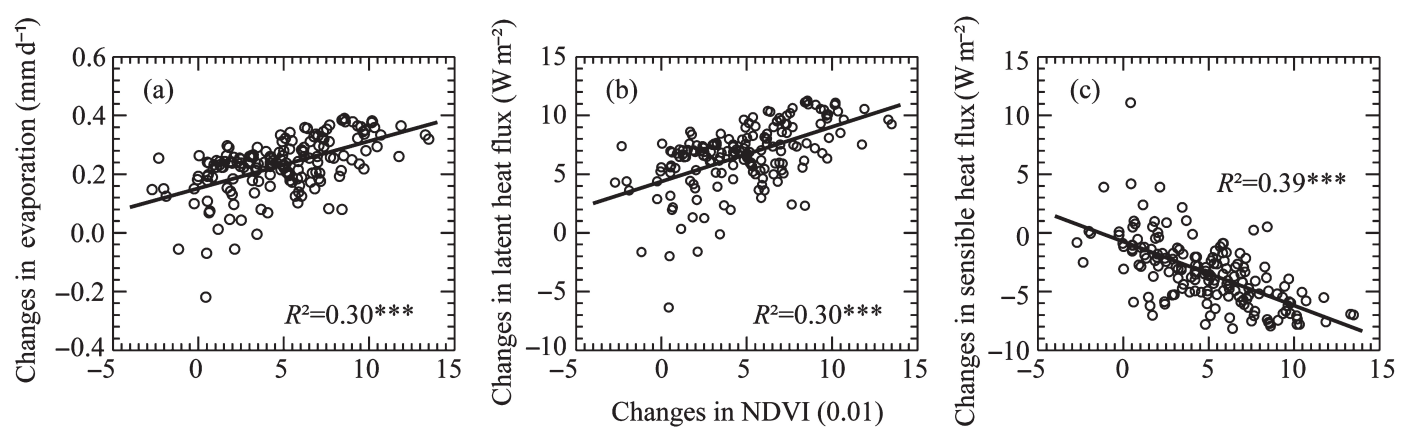

Figure 3. Scatter plots of changes (1990s - 1980s) in NDVI and in surface evaporation (a), latent heat flux (b), and sensible heat flux (c) for all of cropland grid cells at size of $0.5^{\circ} \times 0.5^{\circ}$ across the $\mathrm{NCP}(* * *$ represents correlation is significant at the level of $99.9 \%)$.
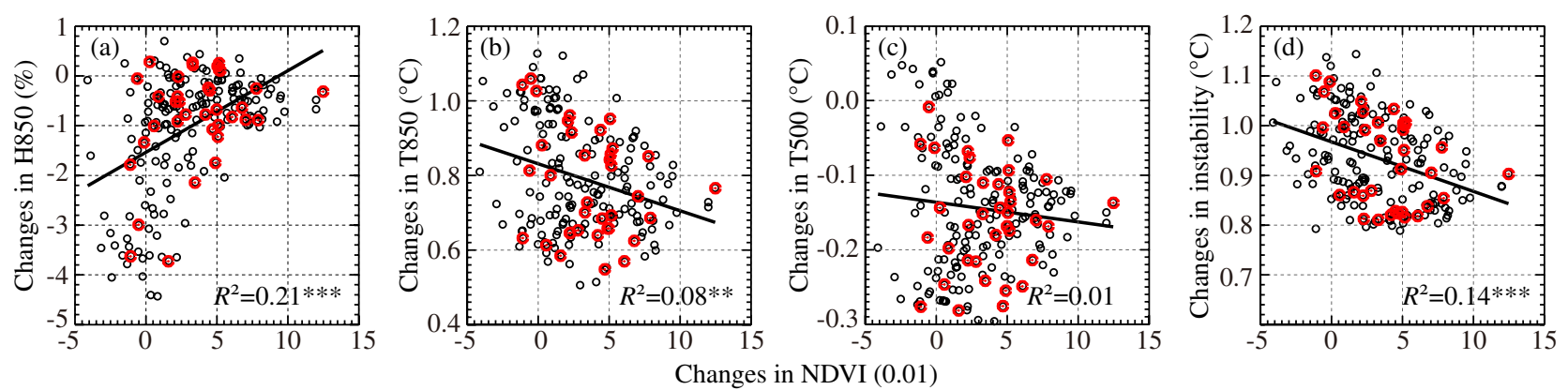

Figure 4. Scatter plots of changes (1980s - 1990s) in NDVI and in specified humidity at a pressure level of $850 \mathrm{hPa}(\mathrm{a})$, temperature at pressure level of $850 \mathrm{hPa}$ (b) and $500 \mathrm{hPa}$ (c), and air column instability (d) for all of cropland grid cells at size of 0.5- by 0.5-degree across the NCP (black circles with red point denote the grid cells in which meteorology sites locate; ** and *** represent correlation is significant at the levels of $99 \%$ and $99.9 \%$, respectively).

\subsection{Effects of air humidity and instability on spring rainfall}

The occurrence of rainfall is necessarily supported by enough moisture in the air and unstable atmosphere. Figure 5 shows the site-based changes in rainfall days and in instability of air column and H850. We could found positive correlations between the changes in rainfall days and in instability of air column (Figure 5(a)-(d); Table 2). The strongest correlation again occurred on the light rainfall $(r=0.69, p<0.001)$ and secondary correlations again occurred on the total rainfall $(r=0.51, p<0.001)$, as the correlations between the changes in NDVI and in rainfall days shown in Figure 1(h) and (i). However, the correlations between changes in $H 850$ and rainfall days are very weak and statistically insignificant (Figure 5(e)-(h)). These correlations suggest that the spatial difference of the changes in rainfall days, especially for light rainfall, is likely resulted from the spatial difference of the changes in air instability due to the cooling effects of the surface greening in the NCP. The change in H850, which is likely related to the wetting effects of the surface greening, has little impacts on the spatial differences of change in rainfall occurrence.

\section{Conclusion and discussion}

The effects of surface greening on spring rainfall in the NCP were investigated using the observed rainfall, satellite-derived vegetation index, and reanalysis data. The correlations between the changes in NDVI and in rainfall, air instability, and low-level atmospheric humid were analysed. The results show that the correlations between the changes in spring NDVI and in rainfall frequency are significantly negative and the strongest correlation occurs on light rainfall. The stations with an increase of $10 \%$ NDVI would experience the light rainfall days/amount decrease by more $\sim 10 \%$. The increased NDVI implicates more evaporation/latent heat flux and less sensible heat flux. As a result, there are detectable wetting and cooling effects on low-level atmosphere, which favours the enhancement of air stability. The enhanced air column stability is able to suppress the occurrence of rainfall and could explain the as much as $48 \%$ of spatial variations of changes in light rainfall; however, the changes in low-level atmospheric humidity is likely having too weak regulation on spatial variations of changes in rainfall occurrence to be detected. These findings supported our conclusion that surface greening may suppress the occurrence of spring rainfall in the NCP from 1980s to 1990s.

It should be noted that the overall spring rainfall decrease in the NCP is likely related to the changes in large-scale circulation and relevant moisture transportation (e.g. Yang and Lau, 2004; Zhao et al., 2012). We also found that the regional rainfall decrease from 1980s to 1990s over NCP occurred along with the decrease in mean total column water $\left(\mathrm{kg} \mathrm{m}^{-2}\right)$. Though the total column water is also likely regulated by the local surface evaporation, 

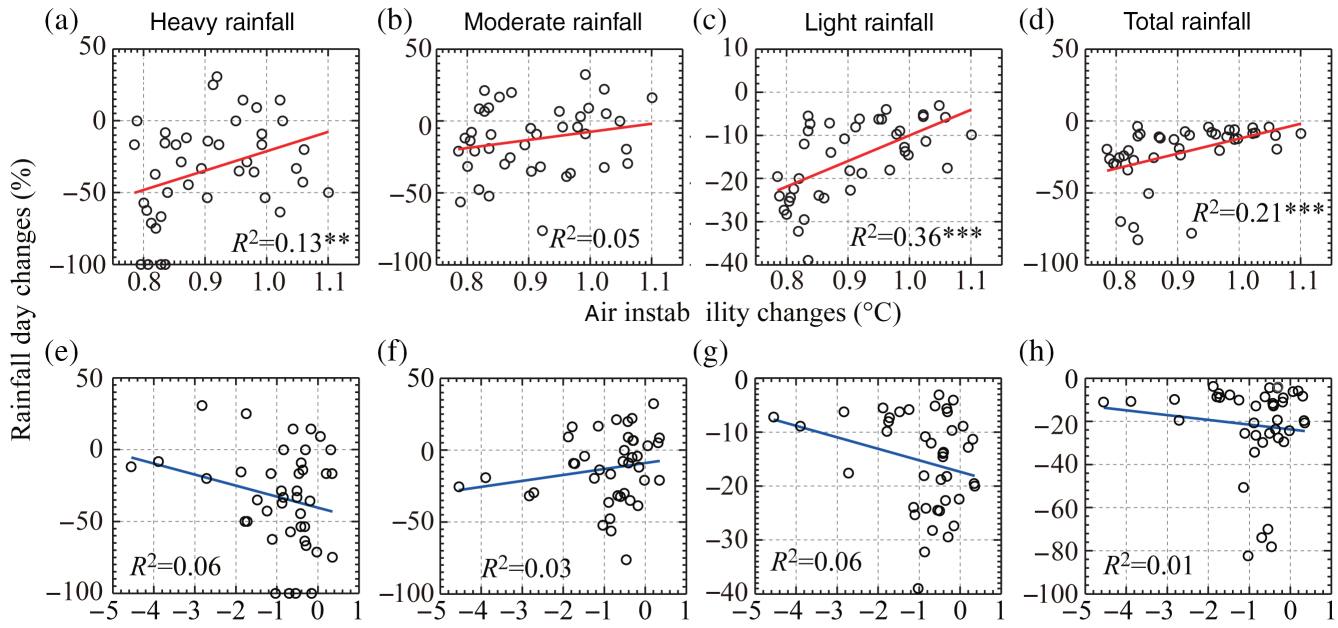

(f)

(g)

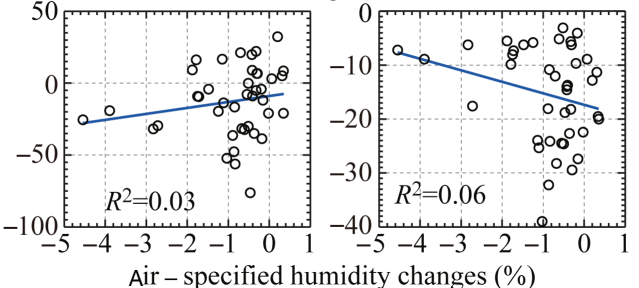

(h)

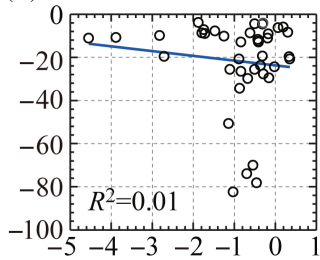

Figure 5. Scatter plot of site-based changes $(1980 \mathrm{~s}-1990 \mathrm{~s})$ in rainfall frequency and in air instability (a-d), in specified humidity of air at a pressure level of $850 \mathrm{hPa}(\mathrm{e}-\mathrm{h})$ for heavy rainfall, moderate rainfall, light rainfall, and total rainfall, respectively, from the site-based measurements $(* *$ and $* * *$ represent correlation is significant at the levels of $99 \%$ and $99.9 \%$, respectively).

Table 2. Correlation coefficients between the changes in rainfall days and in air instability and air-specified humidity.

\begin{tabular}{lcccc}
\hline & Heavy rainfall & Moderate rainfall & Light rainfall & Total rainfall \\
\hline Air instability & $0.36^{* *}$ & 0.22 & $0.60^{* * *}$ & $0.46^{* * *}$ \\
Air-specified humidity & -0.24 & 0.17 & -0.24 & -0.10 \\
\hline
\end{tabular}

$*, * *$, and $* * *$ represent correlation is significant at the levels of $95 \%, 99 \%$, and $99.9 \%$, respectively.

the strength is too weak to produce significant effects on rainfall occurrence. The changes in total column water therefore hardly explain the sptial difference of changes in rainfall. Above findings demontstrate that the surface cooling effects derived from surface greening seems to play a more dominant role than the wetting effect at local scale. Surface greening amplified the local rainfall decrease through cooling the low level of atmosphere to enhance the stability of air column.

Vegetation activity in spring is highly dependent on irrigation due to insufficient precipitation in the NCP (Yuan and Shen, 2013). On the background of rainfall decrease, the surface greening trend is undoubtedly supported by irrigation. Thereby, the observed cooling effects on low-level atmosphere may be partly derived from direct evaporation from irrigation. While there is much still to learn about the interactions between surface greenness and regional climate, the findings shown in this study suggest that irrigation-supported spring greening substantially suppresses local rainfall. Therefore, developing new irrigation technology to enhance the water use efficient and reduce evaporation to weaken the surface cooling effect may be an effective way to promote the rainfall occurrence to save the irrigation cost and water resources.

\section{Acknowledgements}

This research was supported by the China Global Change Research Program (Grant Nos 2010CB950903 and 2010CB951801) from the Ministry of Science and
Technology of China, the National Natural Science Foundation of China (Grant No. 41001122) and the Hundred Talent Program of the Chinese Academy of Sciences, China.

\section{References}

Chen Z, Yang G. 2013. Analysis of drought hazards in North China: distribution and interpretation. Nat. Hazards 65: 279-294, doi: 10.1007/s11069-012-0358-3.

Choi K-S, Kim D-W, Byun H-R. 2010. The regime shift in the early 1980s of spring precipitation in Korea. Int. J. Climatol. 30: 721-732, doi: 10.1002/joc. 1927.

Dee DP, Uppala SM, Simmons AJ, Berrisford P, Poli P, Kobayashi S, Andrae U, Balmaseda MA, Balsamo G, Bauer P, Bechtold P, Beljaars ACM, van de Berg L, Bidlot J, Bormann N, Delsol C, Dragani R, Fuentes M, Geer AJ, Haimberger L, Healy SB, Hersbach H, Holm EV, Isaksen L, Kallberg P, Kohler M, Matricardi M, McNally AP, Monge-Sanz BM, Morcrette JJ, Park BK, Peubey C, de Rosnay P, Tavolato C, Thepaut J-N, Vitart F. 2011. The ERA-Interim reanalysis: configuration and performance of the data assimilation system. $Q$. J. R. Meteorol. Soc. 137: 553-597, doi: 10.1002/qj.828.

Editor Board. 2009. Chinese Terms in Atmospheric Science, 3rd edn. Science Press: Beijing, 14 pp (in Chinese).

Jeong S-J, Ho C-H, Jeong J-H. 2009a. Increase in vegetation greenness and decrease in springtime warming over east Asia. Geophys. Res. Lett. 36: L02710.

Jeong S-J, Ho C-H, Kim K-Y, Jeong J-H. 2009b. Reduction of spring warming over East Asia associated with vegetation feedback. Geophys. Res. Lett. 36: L18705.

Jiang X, Niu G-Y, Yang Z-L. 2009. Impacts of vegetation and groundwater dynamics on warm season precipitation over the Central United States. J. Geographys. Res. 114: D06109, doi: 10.1029/2008JD010756.

Kim Y, Wang G. 2007. Impact of vegetation feedback on the response of precipitation to antecedent soil moisture anomalies over North America. J. Hydrometeorol. 8: 534-550. 
Lee E, Sacks WJ, Chase TN, Foley JA. 2011. Simulated impacts of irrigation on the atmospheric circulation over Asia. J. Geophys. Res. Atmos. 116: D08114, doi: 10.1029/2010JD014740.

Liu J, Liu M, Zhuang D, Zhang Z, Deng X. 2003. Study on spatial pattern of land-use change in China during 1995-2000. Sci. China D Earth Sci. 46: $373-384$.

National Bureau of Statistics of China. 2009. China Agriculture Year Book. China Agriculture Press: Beijing (in Chinese).

Notaro M, Chen G, Liu Z. 2011. Vegetation feedbacks to climate in the global monsoon regions. J. Clim. 24: 5740-5756.

Peng S, Chen A, Xu L, Cao C, Fang J, Myneni RB, Pinzon JE, Tucker CJ, Piao S. 2011. Recent change of vegetation growth trend in China. Environ. Res. Lett. 6: 044027.

Piao S, Fang J, Zhou L, Guo Q, Henderson M, Ji W, Li Y, Tao S. 2003. Interannual variations of monthly and seasonal normalized difference vegetation index (NDVI) in China from 1982 to 1999. J. Geophys. Res. 108(D14): 4401.

Sun S, Wang G. 2014. Climate variability attributable to terrestrial and oceanic forcing in the NCAR CAM3-CLM3 Models. Clim. Dyn. 42: 2067-2078.

Tucker CJ, Slayback DA, Pinzon JE, Los SO, Myneni RB, Taylor MG. 2001. Higher northern latitude normalized difference vegetation index and growing season trends from 1982 to 1999. Int. J. Biometeorol. 45 : 184-190.

Tucker CJ, Pinzon J, Brown M, Slayback D, Park E, Mahoney R, Vermote E, El saleous N. 2005. An extended AVHRR 8-km NDVI data set compatible with MODIS and SPOT vegetation NDVI data. Int. J. Remote Sens. 26: 4485-4498.

Wang Y, Zhao P, Yu R, Rasul G. 2010. Inter-decadal variability of Tibetan spring vegetation and its associations with eastern
China spring rainfall. Int. J. Climatol. 30: 856-865, doi: 10.1002/ joc. 1939 .

Wang G, Sun S, Mei R. 2011. Vegetation dynamics contributes to the multi-decadal variability of precipitation in the Amazon region. Geophys. Res. Lett. 38: L19703, doi: 10.1029/2011GL049017.

Wang F, Notaro M, Liu Z, Chen G. 2014. Observed local remote influences of vegetation on the atmosphere across North America using a model-validated statistical technique that first excludes oceanic forcings. J. Clim. 27: 362-382.

Yang F, Lau K-M. 2004. Trend and variability of China precipitation in spring and summer: linkage to sea-surface temperatures. Int. J. Climatol. 24: 1625-1644, doi: 10.1002/joc.1094.

Yuan Z, Shen Y. 2013. Estimation of agricultural water consumption from meteorological and yield data: a case study of Hebei, North China. PLoS One 8(3): e58685, doi: 10.1371/journal.pone. 0058685 .

Zhang X, Tang Q, Zheng J, Ge Q. 2013. Warming/cooling effects of cropland greenness changes during 1982-2006 in the North China Plain. Environ. Res. Lett. 8: 024038, doi: 10.1088/1748-9326/8/2/ 024038.

Zhao R, Zhang H, Wu G, Li W, Shi A. 2012. Decadal variations in the season advancement of spring water cycle over Eastern China. Sci. China D Earth Sci. 55: 1358-1370, doi: 10.1007/s11430-012-4390-7.

Zhou B, Zhao P. 2010. Influence of the Asian-Pacific oscillation on spring precipitation over central eastern China. Adv. Atmos. Sci. 27: 575-582, doi: 10.1007/s00376-009-9058-7.

Zhou L, Tucker CJ, Kaufmann RK, Slayback D, Shabanov NV, Myneni RB. 2001. Variations in northern vegetation activity inferred from satellite data of vegetation index during 1981 to 1999. J. Geophys. Res. 106: 20069-20083. 